\title{
КИНЕТИКА ФОТОИНИЦИИРОВАННОГО ОКИСЛЕНИЯ 7,12-ДИМЕТИЛБЕНЗ(а)АНТРАЦЕНА В РАЗНЫХ РАСТВОРИТЕЛЯХ
}

В последние годы все большее признание получает гипотеза о возможности использования закономерностей инициированного УФ-излучением окисления бенз(а)пирена (БП) для приближенного моделирования его окислительной деградации в живом организме $\left[{ }^{1,2}\right.$. Однако такая возможность установлена для БП как единственного представителя большой группы химических канцерогенов из числа углеводородов полициклической ароматической природы (ПАУ). Целью настоящего исследования явилось изучение этой возможности относительно 7,12-диметилбенз (а) антрацена (ДМБА) гакже типичного представителя канщерогенных ПАУ, который по своей структуре отличается от бенз(а)пирена (производное пирена) как производное антрацена.

В данной работе приводятся результаты макрокинетической оценки процесса фотоокисления ДМБА в некоторых органических растворителях, которые служат основой для сопоставления с результатами окислительного превращения этого же ПАУ в системax in vivo и с соответствующим поведением БП. Механизму фотоокисления производных антрацена, в том числе и ДМБА, посвящено сравнительно большое число публикаций $\left[{ }^{3-6}\right]$. Однако макрокинетическая характеристика этого процесса в литературе не приведена. Это обстоятельство и послужило основанием для постановки эксперимента, результаты которого излагаются ниже.

\section{Методика}

В эксперименте использовали растворы ДМБА (фирма Fluka AG, Buchs SG) в химически чистом бензоле, н-гексане и $96 \%$-ном водном этаноле при варьировании концентрации от $0,5 \cdot 10^{-4}$ до $1 \cdot 10^{-3} M$. Облучение раствора ДМБА $(20 \mathrm{M \Omega})$ производили в реакционном сосуде емкостью 100 мл с пришлифованной пробкой, которая снабжена крышкойпластиной из прозрачного кварца, с помощью ртутно-кварцевой лампы СВД-120A во всем волновом диапазоне ее излучения (от $240 \mathrm{\mu M} \mathrm{и}$ более, при максимуме испускания 365 нм) или в узкой области около 365 нм при использовании светофильтра УФС-3. Интенсивность излучения определена актинометрически [7] при использовании фильтра в 0,23$0,28 \cdot 10^{16} \kappa в а н т / м \Omega \cdot с е к$ и без фильтра $-1,12-1,64 \cdot 10^{16} \kappa в а н т / м \Omega \cdot с е \kappa$.

В реакционном сосуде при комнатной температуре поддерживали постоянное давление кислорода, концентрация которого в растворе (избыточная по отношению к реагенту) обеспечивалась благодаря интенсивному перемешиванию жидкости на постоянном уровне.

Изменение (снижение) концентрации ДМБА фиксировали спектрофотометрически при длине волны 297 нм, причем в предварительном 
эксперименте была установлена правомерность прямого измерения оптической плотности раствора при данной длине волны.

Для исследования продуктов фотореакции ДМБА из испытуемой смеси при пониженном давлении удаляли растворитель. Остаток наносили на пластину с незакрепленным тонким слоем окиси алюминия (нейтральная, II по Брокману). Разделение продуктов проводили последовательно смесями петролейного эфира $\left(40-70^{\circ} \mathrm{C}\right)$ - хлороформа $(9: 1)$ и бензола - ацетона $(9: 1)$. Адсорбционные спектры продуктов, флуоресцирующие на УФ-свету, сняты для этанольных растворов.

Для определения количества фотоокиси ДМБА в реакционной смеси 0,5 мл пробы наносили на пластину и с накоплением соответствующей фракции после хроматографирования спектрофотометрически измеряли его концентрацию в этанольном растворе при специфичной для максимума поглощения длине волны $298 \mathrm{\mu м}\left(\lg \varepsilon=3,79\left[^{8}\right]\right)$.

В эксперименте с ДМБА обязательно следует учитывать его подверженность аутоокислению на свету.

\section{Результаты исследования}

Результаты проведенного экспериментального исследования (см. таблицу) показывают, что кинетические параметры суммарной фотореакции ДМБА зависят от начальной концентрации его в растворе, природы растворителя и от условий облучения (волновой диапазон и интенсивность излучения). Реакция фотодеградации ДМБА, растворенного в этаноле или в гексане, описывается, независимо от условий облучения, кинетическим уравнением первого порядка. При облучении бензольного раствора ДМБА через фильтр УФС-3 реакция также отчасти удовлетворяет кинетике первого порядка: при концентрации ДМБА $0,5 \cdot 10^{-4} M$ до $50 \%$, а при концентрации $1 \cdot 10^{-3} M$ до $80 \%$ прореагирования исходного ДМБА. Суммарный процесс фотолиза же описывается кинетическим уравнением второго порядка, если облучение проводится в бензоле непосредственно лампой СВД-120 А. На рис. 1 приведены некоторые примеры кинетических кривых, характеризующие фоторазложение ДМБА в разных растворителях. Из представленных кривых видно, что скорость окисления ДМБА уменьшается в ряду: бензол>этанол>гексан. В таблице приведены константы скорости и квантовые выходы фоторазложения ДМБА. По-видимому, порядок реакции фотоокисления, определенный методами формальной кинетики, кажущийся, так как величина константы скорости зависит от концентрации ДМБА в расгворе и либо возрастает либо уменьшается (в случае облучения в бензоле без фильтра) вместе с последней. Исключением может служить реакция в этаноле (фильтр УФС-3), где эта тенденция не выражена.

Так как с уменьшением концентра-ции ДМБА в ходе реакции снижается

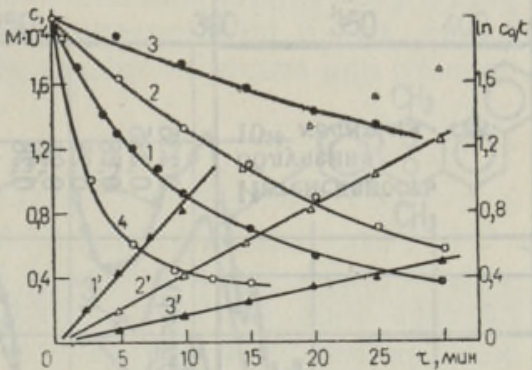

Рис. 1. Кинетика фотоокисления ДМБА в разных растворителях. 1 в бензоле, 2 - в этаноле, 3 - в гексане с использованием светофильтра УФС-3, 4 - в бензоле без светофильтра. $1^{\prime}, 2^{\prime}, 3^{\prime}-$ соответствующие кривые в логарифмических координатах. и скорость фотоокисления, то значения квантовых выходов фотоокисления зависят от отрезка времени (начиная от начала опыта), на котором 


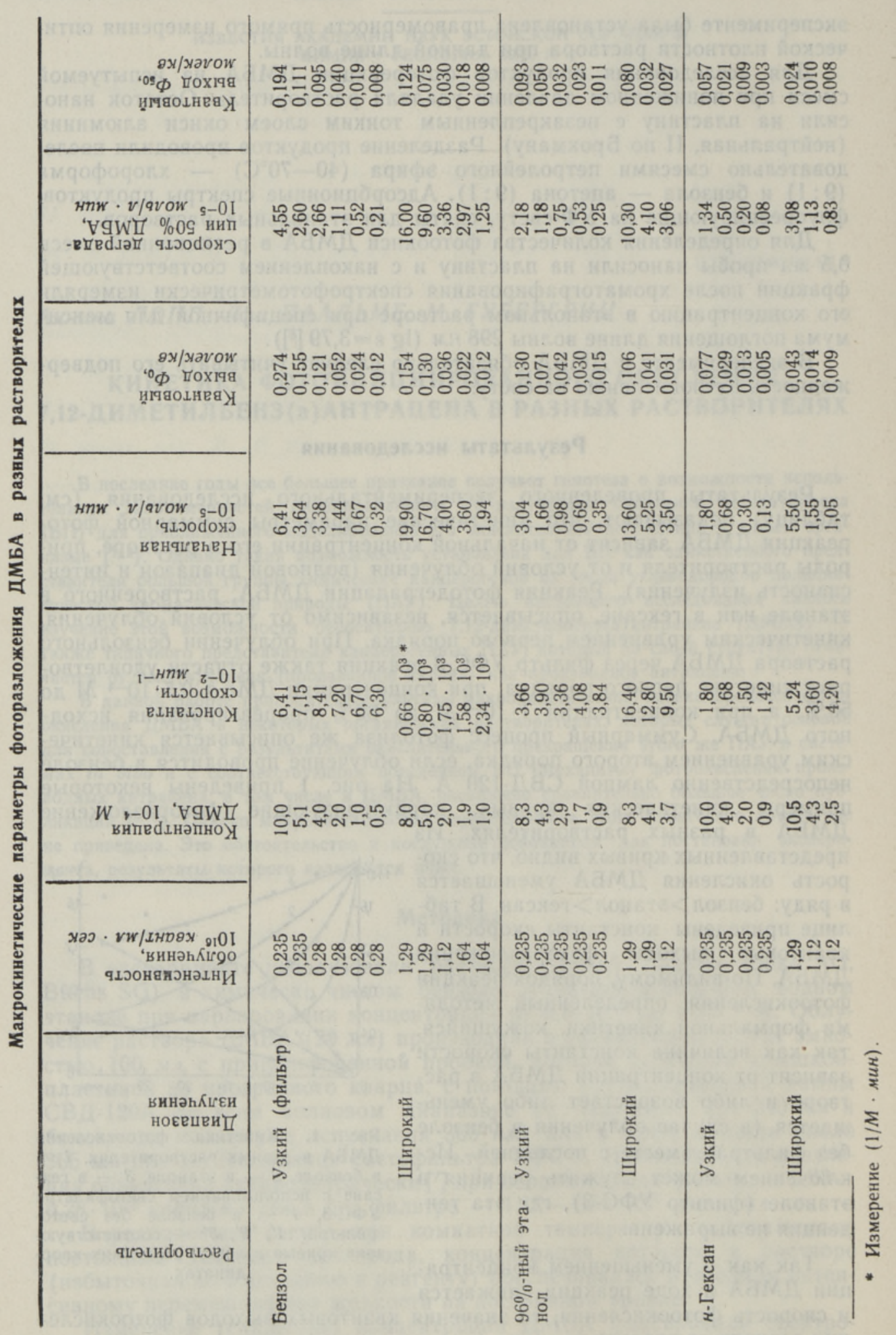


предпринято измерение скорости процесса. В таблице приведены значения квантового выхода, вычисленные либо для начального участка реакции, либо к моменту расходования $50 \%$ ДМБА. В обоих случаях зависимость квантового выхода от концентрации является линейной. На рис. 2 эта зависимость показана для разных условий постановки эксперимента: при облучении через фильтр УФС-3 и без фильтра. Оказывается, что, хотя суммарная скорость деградации ДМБА растет в соответствии с повышением интенсивности излучения (см. таблицу), величина квантового выхода окисления понижена по сравнению со значениями, полученными при облучении ДМБА через фильтр. Очевидно, причиной этого является расходование при облучении ДМБА в широком волновом диапазоне известной части энергии излучения на фотохимические превращения растворителей, причем эта часть энергии не может быть использована полностью (прямо или косвенно) для деградации собственно ДМБА или получаемой реакционной смеси. Чистый октан, близкий по строению и свойствам к

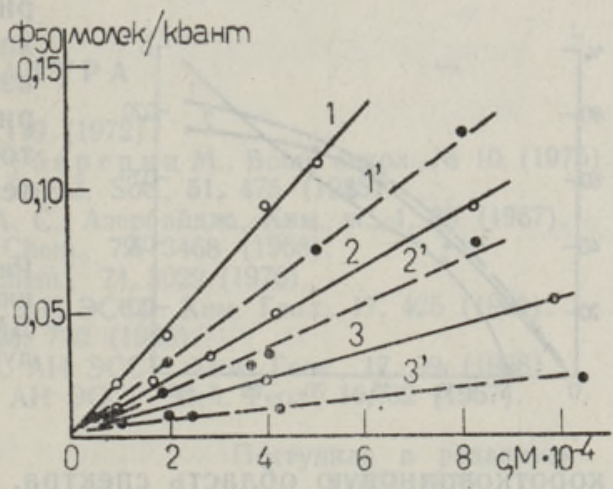

Рис. 2. Зависимость квантового выхода фотодеградации ДМБА от начальной концентрации его в растворе. 1 и $1^{\prime}-$ в бензоле, 2 и $2^{\prime}-$ в этаноле, 3 и $3^{\prime}-$ в гексане при облучении раствора соответственно в узком и широком волновом диапазоне лампы. гексану, также подвергается окислению в аналогичных условиях [9]. Бензол, хотя непосредственно и не подвергается фотоокислению, претерпевает ряд превращений с формированием «полимеров» и продуктов конденсации типа дифенила и 9,10-дифенилантрацена $\left[{ }^{10}\right]$. В случае облучения растворов в узкой волновой области через фильтр УФС-3 растворитель не должен активно участвовать в подобных фотохимических процессах.

Рис. 3. УФ-спектры поглощения продуктов фоторазложения ДМБА и флуоресцентная окраска продуктов (на УФ-свету). 1 - фнолетовая $\rightarrow$ желтая, 2 - синяя $\rightarrow$ фиоле товая, 3 - фиолетовая, 4 - фиолетовая, 5 фиолетовая.

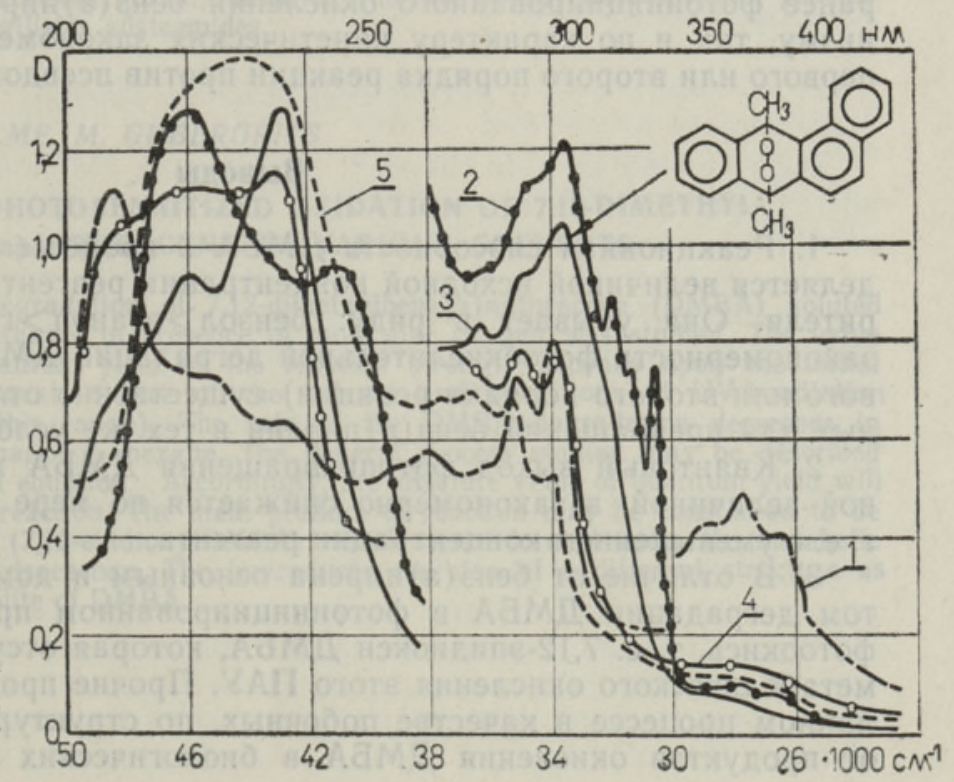


Хроматографический и спектрофотометрический анализы облученного раствора ДМБА показывают, что во всех растворителях кроме фотоокиси (7,12-эпидиокси ДМБА) образуется ряд других продуктов его фотопревращения. Результаты количественного определения фотоокиси (продукт 3 на рис. 3) дают основание считать ее основным и доминирующим продуктом реакции. Кинетика ее образования в бензоле представлена на

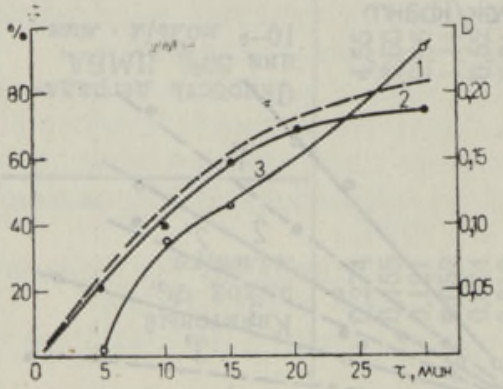
рис. 4. Спектры некоторых наиболее характерных побочных продуктов неизвестного строения приведены на рис. 3. При этом для всех продуктов фотопревращения ДМБА характерно смещение поглощения в более

Рис. 4. Кинетика образования продуктов реакции в случае облучения $1 \cdot 10^{-3} M$ раствора ДМБА в бензоле. 1 - общее количество продуктов реакции, $\% ; 2$ - фотоокись ДМБА, \%; 3 - продукт 2 по оптической плотности.

коротковолновую область спектра. На рис. 3 они представлены в порядке уменьшения $R_{f}$ при использовании указанных выше смесей растворителей для разделения продуктов. C увеличением длительности облучения ДМБА значительно возрастает количество продукта 2 в растворе. На рис. 4 отражена кинетика его образования в бензоле, где величину концентрации этого компонента в реакционной смеси косвенно характеризует оптическая плотность этанольного раствора его при длине волны 300 нм в пересчете на весь начальный объем раствора. Тем не менее этот продукт не играет главенствующей роли в реакционной смеси на любой из стадий фотодеградации ДМБА. На основании рис. 3 и 4 следует в особенности подчеркнуть, что в реакционной смеси продуктов окислительной деградации ДМБА, инициированного УФ-излучением, не удается обнаружить те соединения, которые составляют основную массу продуктов метаболического окисления этого ПАУ в клетке [ $\left.{ }^{8}\right]$. Это обстоятельство существенно отличает рассматриваемый процесс от изученного ранее фотоинициированного окисления бенз(а)пирена [9] как по механизму, так и по характеру кинетических закономерностей (кажущиеся первого или второго порядка реакции против псевдонулевого) .

\section{Выводы}

1. Реакционная способность ДМБА в процессе фотоокисления определяется величиной исходной концентрации реагента и природой растворителя. Она убывает в ряду: бензол>этанол >гексан. Кинетические закономерности фотоокислительной деградации ДМБА (кажущиеся первого или второго порядка реакции) существенно отличны от установленных для превращений бенз(а)пирена в тех же условиях.

2. Квантовый выход фотопревращения ДМБА не является постоянной величиной, а закономерно снижается по мере протекания реакции, т. е. с уменьшением концентрации реагента.

3. В отличие от бенз(а)пирена основным и доминирующим продуктом деградации ДМБА в фотоинициированном процессе является его фотоокись, т. е. 7,12-эпидиокси ДМБА, которая отсутствует в продуктах метаболического окисления этого ПАУ. Прочие продукты, получаемые в данном процессе в качестве побочных, по структуре также отличаются от продуктов окисления ДМБА в биологических системах. Очевидно, 
указанные различия не позволяют использовать фотоинициированное окисление ДМБА в силу специфики его макромеханизма и кинетических закономерностей для моделирования превращений этого соединения в процессе химического канцерогенеза. Этот вопрос нуждается в дополнительном изучении.

\section{Л ИТЕРАТУРА}

1. In om a t a M., N a g a t a C., Gann, 63, 119 (1972).

2. Па а льм е Л., Ки исо У., К а ру Т., Гу бергриц М., Вопр. онкол., № 10, (1975)

3. B ow en E. J., T a n n e r D. M., Trans. Farad. Soc., 51, 475 (1955).

4. Эдил аш в или И. Л., Ч е р ка сов А. С., Азербайдж,, Хим. ж., 1, 86 (1967)

5. Steven s B., Alg a r B. E., J. Phys. Chem., 72, 3468 (1968).

6. Algar B. E., Steven s B., J. Phys. Chem., 74, 3029 (1970).

7. Паальме Л., Губергриц М., Изв. АН ЭССР. Хим. Геол., 17, 425 (1968),

8. B o y l a nd E., Sim s. P., Biochem. J., 95, 780 (1965).

9. Паа льме Л., Губергряц М., Изв. АН ЭССР. Хим. Геол., 17, 99 (1968).

10. П а альме Л., Г у бе р гриц М., Изв. АН ЭССР. Хим. Геол., 16, 32 (1967).

$\begin{array}{cc}\text { Ннститут химии } & \text { Поступила в редакцию } \\ \text { Академии наук Эстонской ССР } & 21 / \mathrm{IV} 1975\end{array}$

Annika LOPP, Lia PAALME, M. GUBERGRITS

\section{7,12-DIMETUOLBENS(a)ANTRATSEENI FOTOINITSIEERITUD OKSODEERIMINE ERINEVATES LAHUSTITES}

Uuriti 7,12-dimetüülbens(a) antratseeni (DMBA) lagunemist ultraviolettkiirguse mõjul benseeni-, heksaani- ja etanoolilahuses. Leiti, et lagunemise kiiruse määravad aine algkontsentratsioon lahuses, lahusti loomus ja kiiritamistingimused (kiirguse intensiivsus ja lainepikkus). Fotoreaktsiooni kiiruse järgi reastuvad lahustid järgmiselt (kahanevas reas): benseen, etanool, heksaan. Kui kiiritamine toimub valgusfiltriga УФС-3 ja piiratud lainepikkuste vahemikus, siis on reaktsioon DMBA suhtes esimest järku kốikides nimetatud lahustites. Reaktsiooni kiiruse vähenedes väheneb ajaliselt ka reaktsiooni kvantsaagis.

Fotoinitsieeritud lagunemise pōhiproduktiks on 7,12-epidioksüdimetüülbens (a) antratseen (fotooksiid), ka reaktsiooni kõrvalproduktid erinevad DMBA oksüdatsiooni produktidest, mis tekivad bioloogilistes süsteemides.

\section{Annika LOPP, Lia PAALME, M. GUBERGRITS}

\section{KINETICS OF PHOTOSENSITIZED OXIDATION OF 7,12-DIMETHYL- BENZ(a)ANTHRACENE IN VARIOUS SOLVENTS}

The photochemical degradation of 7,12-dimethylbenz(a)anthracene (DMBA) soluted in benzene, hexane and ethanol in presence of molecular oxygen was studied. The value of rate constant and quantum yield of the reaction strongly depends upon the initial concentration of the reagent, nature of the solvent and conditions of UV-irradiation (intensity and wavelength's range). The rate of the DMBA degradation decreases in the order: benzene $>$ ethanol $>$ hexane. The general process studied may be described by the first-order reaction equation. Accordingly, the absolute value of quantum yield will change with the time of reaction. The main product of reaction may be considered to be the photooxide of DMBA (7,12-epidioxy-DMBA), which is not formed under the metabolic oxidation of the same hydrocarbon. The byproducts are also of a different structure as compared with the metabolite of DMBA. 